\title{
La protección de la privacidad en la jurisprudencia chilena reciente
}

\author{
The Protection of Privacy in Recent Chilean \\ Judicial Rulings
}

Rodrigo P. Correa G.*

Recepción: 05/07/2018

Evaluación: 31/07/2018

Aceptación final: 08/08/2018

Resumen: el trabajo da cuenta críticamente de la jurisprudencia del Tribunal Constitucional y de la Corte Suprema de Chile sobre privacidad. Identifica los criterios utilizados para calificar como privada una comunicación establecida en Internet, sea mediante programas para compartir archivos en una red de usuarios (P2P) o mediante correo electrónico. Discute los niveles de protección otorgados al hogar, a los espacios privados abiertos, tales como jardines y terrazas y a los espacios públicos, frente al registro de imágenes realizado por el Estado con fines de seguridad pública. Finalmente, analiza la jurisprudencia sobre protección de la privacidad frente a particulares, sean periodistas interesados en registrar conversaciones privadas para generar noticias, trabajadores interesados en registrar conversaciones con sus empleadores para utilizarlas como evidencia en juicio, o empleadores interesados en registrar documentos privados de sus trabajadores para pesquisar actos desleales con la empresa.

Palabras clave: privacidad, comunicaciones, registro.

Profesor Titular, Facultad de Derecho, Universidad Adolfo Ibáñez, Chile. Correo electrónico: rodrigo.correa@uai.cl Agradezco a Juan Pablo Aristegui Spikin, a Nicolás Sanhueza Toro y a un evaluador anónimo, quienes leyeron un borrador del texto y advirtieron numerosos errores. 
Rodrigo P. Correa G.

\begin{abstract}
The text offers a critical account of Chilean Constitutional Court and Supreme Court's rulings on privacy. It identifies the criteria used to qualify as private an internet-based communication stablished in order to share files through programs in a users' network (P2P) or through electronic mail. It discusses the levels of protection granted to houses, private open spaces such as gardens and terraces, and public spaces against the registration of images made by the State for public security purposes. Finally, it analyzes legal precedents regarding privacy protection against individuals, such as specialized journalists interested in the registration of private conversations with the aim of producing news, or employees interested in registering conversations with their employers in order to use them as evidence in court, or employers interested in registering private documents of their employees to investigate presumable disloyal acts.
\end{abstract}

Key words: privacy, communications, registration.

\title{
Introducción
}

La jurisprudencia sobre privacidad en Chile tiene su apoyo en las siguientes disposiciones constitucionales ${ }^{1}$ :

Art. 19. La Constitución asegura a todas las personas:

$4^{\text {o. }}$ - El respeto y protección a la vida privada...

$5^{\circ}$.- La inviolabilidad del hogar y de toda forma de comunicación privada. El hogar sólo puede allanarse y las comunicaciones y documentos privados interceptarse, abrirse o registrarse en los casos y formas determinados por la ley...

La disposición del numeral quinto constituye un desarrollo de las inviolabilidades del hogar, de la correspondencia epistolar y telegráfica, de las comunicaciones telefónicas y de los papeles o efectos públicos, reconoci-

Toda la jurisprudencia citada está públicamente disponible en Internet y se la puede encontrar con el número de rol. La del Tribunal Constitucional está disponible en www.tribunalconstitucional.cl. La de la Corte Suprema y Cortes de Apelaciones está disponible en https://oficinajudicialvirtual.pjud.cl/frameInv.php. 
La protección de la privacidad en la jurisprudencia chilena reciente

das en los numerales 12 y 13 del artículo 10 de la Constitución de $1925^{2}$ y con diversos antecedentes en el derecho comparado. La disposición del numeral cuarto constituye una innovación introducida por primera vez en el Acta Constitucional No 3 de $1976^{3}$. Son dos en consecuencia las direcciones en que la Constitución Política de la República de Chile de 1980 (enadelante, la "Constitución"4) amplía la protección de la privacidad respecto de la Constitución de 1925: por una parte, expande el ámbito de protección frente al Estado; por otra parte, introduce un mandato de protección estatal que ciertamente comprende el deber de tutelar la privacidad también frente a su vulneración por particulares. Lo primero es resultado de la sustitución de la frase "correspondencia epistolar y telegráfica y... comunicaciones telefónicas" por la genérica "comunicaciones privadas"; la sustitución de "papeles o efectos públicos" por "documentos privados" $\mathrm{y}$, finalmente, la incorporación de una obligación de respeto de la "vida privada". Lo segundo es consecuencia de la explícita introducción de un mandato de "protección a la vida privada" en el numeral cuarto transcrito.

Junto con ampliar la protección de la privacidad, la Constitución de 1980 aumentó la indeterminación del ámbito protegido. Ello se debe a que las categorías más amplias a las que recurre tienen contornos menos pre-

2 Las disposiciones citadas eran del siguiente tenor: Asimismo, la Constitución asegura a todos los habitantes de la República: ... 12 $2^{\circ}$ La inviolabilidad del hogar. La casa de toda persona que habite el territorio chileno sólo puede ser allanada por un motivo especial determinado por la ley, y en virtud de orden de autoridad competente; $13^{\circ} \mathrm{La}$ inviolabilidad de la correspondencia epistolar y telegráfica y de las comunicaciones telefónicas. No podrán abrirse, ni interceptarse, ni registrarse los papeles o efectos públicos, sino en los casos expresamente señalados por la ley... La protección de las comunicaciones telefónicas fue incorporada por ley de reforma constitucional № 17.398, de 9 de enero de 1971.

3 Artículo primero, numeral décimo. La Constitución de 1980, vigente desde el 11 de marzo de 1981, introdujo dos cambios a esta regulación. Por una parte, incorporó una garantía de respeto y protección a la vida pública. Por otra parte, estableció un mandato de incriminación del delito de difamación. Ambos cambios fueron derogados por la ley de reforma constitucional 20050, de 26 de agosto de 2005, que restableció el texto del Acta Constitucional No 3 .

4 La Constitución ha sido reformada por 39 leyes desde su promulgación. Las disposiciones constitucionales pertinentes para el presente trabajo fueron modificadas por última vez por ley de reforma constitucional 20.050, de 26 de agosto de 2005. Salvo que se indique lo contrario, todas las referencias a la Constitución Política se hacen al texto modificado por la citada ley. 
cisos que las anteriores. La determinación de qué cuenta como una comunicación epistolar, telegráfica o telefónica, bajo la Constitución de 1925, no estaba sujeta a la dificultad que plantea el texto actualmente vigente de establecer cuándo una comunicación debe entenderse privada o qué circunstancias deben estimarse ser parte de la "vida privada". A esta indeterminación, que es consustancial a la técnica utilizada, se suma aquella que resulta de los cambios en las formas de interacción social que ha favorecido el desarrollo tecnológico ${ }^{5}$. Esta indeterminación de doble fuente ofrece un campo amplio para el desarrollo legal y jurisprudencial.

El objeto del presente trabajo es dar cuenta de la manera en que la Corte Suprema y el Tribunal Constitucional, mediante algunas sentencias recientes, han intentado trazar criterios interpretativos en el ámbito de la protección de la privacidad ${ }^{6}$. En la primera sección se reportará alguna jurisprudencia relativa a la inviolabilidad de las comunicaciones privadas por parte del Estado (1). En la segunda, se reseñará una sentencia relativa a la protección de espacios privados frente a intromisiones estatales (2). La tercera sección, ya en el ámbito del mandato de protección de la vida privada frente a particulares, examinará sentencias que contribuyen a delimitar el significado de "vida privada" y "comunicaciones privadas" en relación con dicho mandato (3).

\section{1.}

La Constitución Política de la República de Chile asegura la "inviolabilidad... de toda forma de comunicación privada”, las que sólo pueden "inter-

5 El alcance o extensión del mandato de "protección a la vida privada" constituye una tercera fuente de indeterminación que, sin embargo, no parece haber dado hasta ahora problemas a la jurisprudencia chilena. Esto probablemente se debe a que los tribunales chilenos rutinariamente admiten que la acción de amparo de derechos constitucionales-recurso de protección-puede dirigirse contra particulares. En consecuencia, cualquier déficit de protección legal de la vida privada, no se traduce en una demanda contra el Estado por falta de protección, sino en una demanda de protección ad hoc por parte de los tribunales.

6 No se trata de un reporte exhaustivo de la jurisprudencia. El volumen de causas que resuelve la Corte Suprema es tal que semejante reporte exigiría de una investigación de una envergadura muy superior a la que dio lugar el presente trabajo. 
La protección de la privacidad en la jurisprudencia chilena reciente

ceptarse, abrirse o registrarse en los casos y formas determinados por la ley". Un primer problema dice relación con la calificación de una comunicación como privada. La jurisprudencia ha oscilado entre dos criterios de calificación: las condiciones pragmáticas del acto de comunicación y la presencia o ausencia de interés público en el contenido de la comunicación. El primer criterio, aunque aplicado en forma contradictoria, ha sido preferido cuando la afectación a la privacidad proviene del Estado. Cuando la afectación proviene de particulares, la jurisprudencia más reciente tiende a favorecer el criterio de interés público (véase sección 3 infra).

Ejemplo del criterio que atiende a las condiciones pragmáticas de la comunicación es lo resuelto por la Corte Suprema en sentencia de 18 de agosto de 2009 (rol 3557-2009). Dos personas fueron condenadas como autoras del delito de almacenamiento de material pornográfico infantil ${ }^{7}$. Los condenados recurrieron a la Corte Suprema reclamando infracción sustancial de la garantía de inviolabilidad de las comunicaciones privadas durante la etapa de investigación ${ }^{8}$. Según declaraciones de la policía que fueron tenidas por buenas por la Corte, la investigación se realiza con asistencia de un sistema informático denominado HASH. La policía no solicita autorización judicial para utilizar el sistema, pues asume que este no afecta garantía constitucional alguna. El sistema consta de dos subsistemas. El primero es una base de datos de archivos electrónicos de pornografía infantil. El segundo es un algoritmo que analiza el tráfico en la red Internet mediante programas para compartir archivos en una red de usuarios ("peer to peer" o $\mathrm{P} 2 \mathrm{P}$ ) y detecta cuando un usuario está descargando un archivo que coincide con alguno de los que se encuentran en la base de datos. Cuando ello ocurre, el sistema reporta el número de protocolo internet

7 El artículo 374 bis del Código Penal dispone: "El que maliciosamente adquiera o almacene material pornográfico, cualquiera sea su soporte, en cuya elaboración hayan sido utilizados menores de dieciocho años, será castigado con presidio menor en su grado medio".

8 El artículo 373(a) del Código Procesal Penal dispone: "Procederá la declaración de nulidad del juicio oral y de la sentencia... Cuando, en cualquier etapa del procedimiento o en el pronunciamiento de la sentencia, se hubieren infringido sustancialmente derechos o garantías asegurados por la Constitución o por los tratados internacionales ratificados por Chile que se encuentren vigentes..." Por disposición del artículo 376 inciso primero del mismo Código, conoce del recurso de nulidad la Corte Suprema. 
Rodrigo P. Correa G.

(IP) del usuario que ha descargado el archivo, así como la fecha y hora de la descarga. Todo este proceso es automatizado. La policía no examina las descargas que hace el usuario ni dirige el sistema hacia un usuario en particular, sino que simplemente toma medidas investigativas adicionales cuando el sistema emite un reporte positivo. En ese momento, luego de identificar a qué prestador de servicio de Internet pertenece el número de protocolo internet reportado por el sistema, solicita a dicho prestador identificar al titular del contrato de prestación de servicio. Con el reporte del sistema HASH y la identidad del titular del contrato, la fiscalía solicita una orden de entrada, registro e incautación. En la investigación que dio lugar a la condena en el caso que se comenta, la policía encontró archivos de pornografía infantil en los computadores incautados.

El recurso de nulidad se fundaba en el carácter privado de la comunicación establecida mediante el programa P2P emule. Tratándose de una comunicación privada, protegida por la garantía constitucional de la inviolabilidad, la policía solo podía interceptar la comunicación "en los casos y formas determinados por la ley”. De conformidad con lo dispuesto en el artículo 9 del Código Procesal Penal, dicha interceptación requería autorización judicial previa ${ }^{9}$. La Corte desestimó estas alegaciones. Tuvo para ello presente las siguientes condiciones en que se producía la comunicación que permitía descargar los archivos: (1) que la red Internet, en que se realizó la comunicación, es de acceso público; (2) que el programa utilizado para establecer la comunicación (emule o emule plus) es de libre disposición y, (3) que la comunicación se establece anónimamente entre múltiples usuarios, sin que haya destinatarios "prefijados". Aunque la sentencia no es todo lo clara que uno quisiera, pareciera que la concurrencia conjunta de estos tres elementos es lo que configura "un mercado abierto para obtener... información pornográfica infantil” (considerando 19). Por esta razón negó que la comunicación tuviera carácter privado. Resulta de interés contrastar esta conclusión con lo resuelto por el Tribunal Constitucional en la sentencia que se comenta a continuación.

9 El artículo 9 del Código Procesal Penal dispone: “Toda actuación del procedimiento que privare al imputado o a un tercero del ejercicio de los derechos que la Constitución asegura, o lo restringiere o perturbare, requerirá de autorización judicial previa". 
La protección de la privacidad en la jurisprudencia chilena reciente

La Constitución ha establecido la publicidad de "los actos y resoluciones de los órganos del Estado, así como sus fundamentos y los procedimientos que utilicen" (artículo 8, inciso primero). Evidentemente esta publicidad puede afectar la privacidad de los particulares. Es por ello que la misma Constitución permite que la ley establezca la reserva o secreto, inter alia, cuando la publicidad afecte los derechos de las personas ${ }^{10}$.

La ley 20285, sobre acceso a la información pública (en adelante, "Ley de Acceso a la Información") desarrolla estos principios constitucionales. Ella autoriza a cualquier persona a requerir del Estado cualquier información que no esté sujeta a secreto o reserva. Frente a tal requerimiento, la privacidad de terceros está protegida tanto material como procedimentalmente. Materialmente, está sujeta a reserva o secreto la información cuya "publicidad, comunicación o conocimiento afecte... la esfera de... [la] vida privada" de las personas (Ley de Acceso a la Información, artículo 21 № 2). Procedimentalmente, la autoridad requerida deberá notificar por escrito a los terceros a quienes pudiera afectar la solicitud. Estos pueden oponerse dentro de un breve plazo, en cuyo caso la autoridad requerida queda impedida de entregar la información. El solicitante puede sin embargo deducir un amparo ante un órgano administrativo autónomo llamado Consejo para la Transparencia (id., artículo 24; en adelante, "el Consejo"), el que puede ordenar la entrega de la información requerida si estima que no concurre causal de secreto o reserva.

Para el cumplimiento de sus fines, la administración pública requiere información privada. Parte importante de esta información es entregada por los propios particulares, usualmente por mandato legal. El Estado dispone en consecuencia de mucha información privada, la que puede ser objeto de solicitudes de entrega por cualquier persona. Resulta por ello imprescindible determinar bajo qué condiciones una determinada información pertenece a la vida privada de las personas.

${ }^{10}$ Esta ley está sujeta a una exigencia de quórum calificado: debe ser aprobada por la mayoría de los diputados y senadores en ejercicio. Las otras hipótesis que autorizan a la ley a establecer la reserva o secreto son "cuando la publicidad afectare el debido cumplimiento de las funciones de... [los] órganos [del Estado]... la seguridad de la Nación o el interés nacional". 
Rodrigo P. Correa G.

Hay sin embargo una segunda dimensión del problema. Se trata de determinar no ya si el contenido de la información que el Estado posee es privada, sino si la comunicación entre un particular y el Estado tiene carácter privado a efecto de la protección del artículo 19 No 5 de la Constitución. De este problema tocó conocer al Tribunal Constitucional.

El año 2015 una persona solicitó al Servicio Nacional de Pesca y Acuicultura (en adelante, "Sernapesca") información relativa a comunicaciones entre dicho servicio y la Asociación de la Industria del Salmón de Chile A.G. (en adelante, "SalmonChile"), asociación gremial de las principales empresas de la industria salmonera. La información solicitada incluía copia de correspondencia electrónica intercambiada entre las partes entre los años 2014 y 2015. Sernapesca notificó de la solicitud a SalmonChile, la que se opuso a su entrega. El solicitante recurrió de amparo al Consejo, el que desestimó que la información solicitada se encontrara sujeta a secreto o reserva y ordenó a Sernapesca entregarla. Contra esta resolución del Consejo, Sernapesca dedujo reclamo de ilegalidad ante la Corte de Apelaciones de Santiago. Pendiente este reclamo, dedujo recurso de inaplicabilidad por inconstitucionalidad ante el Tribunal Constitucional. En virtud de este recurso, el Tribunal tiene competencia para declarar la "la inaplicabilidad de un precepto legal cuya aplicación en cualquier gestión que se siga ante un tribunal ordinario o especial, resulte contraria a la Constitución”. Sernapesca solicitaba declaración de inaplicabilidad de las disposiciones de la Ley de Acceso a la Información en virtud de las cuales el Consejo le había ordenado entregar la correspondencia electrónica.

En sentencia de 27 de diciembre de 2016 el Tribunal entendió que debía determinar, en primer lugar, si dicha correspondencia electrónica constituía per se una comunicación privada protegida por la garantía constitucional de la inviolabilidad ${ }^{11}$. Las circunstancias relevantes eran las siguientes: a) correspondencia intercambiada por correo electrónico por Internet; b) utilizando uno de los interlocutores cuenta de correo electrónico oficial y c)

${ }^{11}$ Chile, Tribunal Constitucional, rol 2982-2016, sentencia de 27 de diciembre de 2016, disponible en http://www.tribunalconstitucional.cl/descargar_expediente2.php?id=59383. La sentencia fue acordada por mayoría de los ministros Carmona (redactor), Peña, Aróstica, Romero, Brahm, Letelier y Vásquez, y voto en contra de García (redactor), Hernández y Pozo. 
La protección de la privacidad en la jurisprudencia chilena reciente

equipos de propiedad del servicio público; d) uno de los interlocutores era funcionario estatal y, e) la correspondencia tuvo lugar en razón del cargo público que servía uno de los interlocutores.

El Tribunal fue categórico respecto de la primera circunstancia. Sostuvo que los correos electrónicos:

son comunicaciones que se transmiten por canales cerrados, no por canales abiertos, y tienen emisores y destinatarios acotados. Por lo mismo, hay una expectativa razonable de que están a cubierto de injerencias y del conocimiento de terceros. En nada obsta a lo anterior el que no sea muy dificultoso interceptarlos o abrirlos. Nada más simple que abrir una carta. Pero, desde hace doscientos años, nuestras constituciones han procurado precaver esa invasión. El correo no necesita ir encriptado o con técnicas de cifrado para recibir la protección del artículo $19, \mathrm{~N}^{\circ} 5^{\circ}$. El amparo está dado por el hecho de llevarse a efecto por un mecanismo técnico cerrado (considerando 33).

El Tribunal estableció una correlación entre la expectativa de privacidad de los interlocutores y dos condiciones pragmáticas bajo las cuales se produjo la comunicación: canal cerrado y destinatarios acotados. Luego estimó que todas las demás circunstancias de la comunicación eran irrelevantes para alterar la conclusión de que ella se encontraba constitucionalmente protegida.

Después de descartar que la facilidad de la interceptación determinara que la comunicación por correo electrónico no estuviera protegida, el tribunal desestimó que los correos quedaran sin protección constitucional por ser enviados por funcionarios públicos ${ }^{12}$. Ofreció para ello tres argumentos. Primero, que lo protegido es la comunicación, con independencia de su carácter público o privado. Segundo, que no hay norma constitucional que excluya a los funcionarios públicos de la garantía de la inviolabilidad de las

${ }^{12}$ La sentencia afirma que "no cambia la naturaleza de comunicación privada el que los correos emanen de funcionarios públicos". Los hechos de la causa no permiten afirmar que todos los correos solicitados hubieran sido enviados por funcionarios públicos. Ellos más bien sugieren que los funcionarios eran tanto emisores como destinatarios de los mismos. La sentencia no repara en esta circunstancia. Es posible que la mayoría haya pensado que, 
Rodrigo P. Correa G.

comunicaciones. Tercero, que la propiedad estatal de las cuentas de correo y de los equipos utilizados tampoco resultaba determinante, pues "nadie diría que las conversaciones telefónicas, por el hecho de realizarse por un teléfono que proporciona el servicio, cuya interconexión paga el mismo, pueden escucharse, grabarse y/o difundirse. Para correos electrónicos, debe aplicarse la misma lógica" (considerando 34).

La debilidad de la fundamentación de la sentencia fue puesta en evidencia por el voto de minoría:

Lo protegido por... [la garantía de la inviolabilidad de las comunicaciones privadas] es el proceso de comunicación mientras éste se realice... La fortaleza de este derecho se logra transformando en invulnerable el medio a través del cual se realiza, sin importar el contenido de lo comunicado;

$19^{\circ}$. Que en este caso... el proceso de comunicación ya se encuentra finalizado y el contenido de esos correos, si bien puede constituir el objeto protegido por derechos fundamentales, la Ley No 20.285 contempla mecanismos para evitar afectar los derechos de terceros... [sic; considerandos 18 y 19 ]

Esta crítica devela que el Tribunal erró al situar el problema en la garantía de la inviolabilidad de las comunicaciones privadas, en circunstancias que se trataba de examinar si se amenazaba con vulnerar la inviolabilidad de documentos privados. En este sentido, la analogía que estableció el Tribunal entre las conversaciones telefónicas y el correo electrónico no resulta convincente. Lo cierto es que aquellas conversaciones tienen peculiaridades que las comunicaciones por correo electrónico no comparten. Es característico de la conversación telefónica que ella no queda per se registrada. Ciertamente la empresa telefónica registra el hecho de su ocurrencia, su fecha y hora, su duración, el número que inició la llamada y el que la recibió. Pero del contenido de la conversación no queda registro alguno. Con el correo electrónico no ocurre igual. La comunicación se produce

si los correos electrónicos enviados por funcionarios públicos están constitucionalmente 
La protección de la privacidad en la jurisprudencia chilena reciente

mediante su registro, el que queda disponible tanto para el emisor como para el receptor, quienes lo pueden eliminar para sí, pero no para la contraparte. En consecuencia, la comunicación por correo electrónico puede ser directamente conocida por terceros ajenos a la misma tanto mediante interceptación del acto de comunicación (aquello que en opinión de los disidentes constituye una vulneración de la garantía de la inviolabilidad de las comunicaciones privadas), como mediante el posterior acceso al registro de dicha conversación (vulneración a la garantía de inviolabilidad de los documentos privados). Del mismo modo, una carta puede ser interceptada y abierta antes de que llegue a su destinatario (comunicación privada) como leída sin autorización de su destinatario una vez que este ya la leyó y la guardó (documento privado).

Esta distinción es importante. Quien envía una carta o un correo electrónico confía razonablemente en que la comunicación llegará a su destinatario sin ser vista por terceros. El derecho protege esta expectativa mediante la garantía de la inviolabilidad de las comunicaciones privadas. Pero la expectativa de que una vez recibida, la comunicación no sea vista por terceros, solo es razonable dependiendo de las circunstancias. El destinatario puede ser indiscreto o descuidado. Quien envía la comunicación asume el riesgo de la indiscreción o negligencia. El derecho no protege la expectativa de exclusión de terceros una vez que la comunicación ha sido recibida por su destinatario. Sí protege el documento (carta o mensaje electrónico) utilizado para comunicarse en la medida en que su dueño lo mantenga bajo condiciones que permitan calificarlo de privado ${ }^{13}$.

Tratándose de funcionarios estatales la distinción entre comunicación y documento en que queda registrado el contenido de la comunicación es particularmente importante. El funcionario puede estar sujeto a la obligación de archivar la correspondencia enviada y recibida, y a la prohibición de borrar los mensajes electrónicos enviados y recibidos. Estos documentos

${ }^{13}$ En el mismo sentido, Chile, Corte Suprema, sentencia de 17 de agosto de 2017 (rol 182792017), Matus disidente, numeral 3. 
Rodrigo P. Correa G.

podrían ser revisados por su superior jerárquico en cumplimiento de su función de control y supervisión ${ }^{14}$.

Considerado así, se comprende que la sentencia yerra doblemente al sostener que no hay norma constitucional que excluya a los funcionarios públicos de la garantía de la inviolabilidad de las comunicaciones con el argumento de que "[s]i aceptáramos que las comunicaciones de los funcionarios, por el hecho de ser tales, no están protegidas por el artículo 19, $\mathrm{N}^{\circ} 5^{\circ}$, cualquiera podría interceptar, abrir o registrar esas comunicaciones". Por una parte, no se trataba de determinar el carácter de comunicación privada de la correspondencia electrónica entre un servicio público y un particular, sino de si correspondía calificar de documentos privados los registros de dicha correspondencia en poder de dicho servicio. La eventual respuesta negativa a esta pregunta en modo alguno determina que la primera cuestión deba también contestarse negativamente. Por otra parte, es un error del Tribunal asumir que la conclusión de falta de protección constitucional significa ausencia de toda protección. Es perfectamente posible afirmar que una comunicación o un documento no son privados, y por tanto carecen de protección constitucional, pero que no obstante tienen protección penal, civil o administrativa. Ello es perfectamente consistente con el artículo octavo de la Constitución antes citado, que reconoce al legislador la posibilidad de establecer el secreto o reserva en consideración a "los derechos de las personas", y no solo a la garantía de la inviolabilidad de las comunicaciones privadas.

Por otra parte, al situar el problema en el ámbito de la inviolabilidad de los documentos privados, el problema constitucional se disuelve y queda solo el problema de legalidad. Aun concediendo que las comunicaciones

${ }^{14}$ La Corte de Apelaciones de Santiago ha resuelto en sentencia de 9 de febrero de 2018 (rol 2134-2017), que el empleador puede registrar la correspondencia electrónica del trabajador cuando tiene fundadas sospechas de que éste entrega información a la competencia (a la fecha de entrega de este trabajo, se encuentra pendiente ante la Corte Suprema la declaración de admisibilidad del recurso de unificación de jurisprudencia). Por cierto, en materia laboral esta facultad de inspección y control encuentra su fundamento en el derecho de propiedad del empleador. Tratándose del Estado, ella descansa en la necesidad de legitimación democrática material del ejercicio de potestades públicas. Véase Böckenförde, E.W., "La Democracia como Principio Constitucional", en Estudios sobre Estado de Derecho y Democracia, Madrid, Trotta, 2000, pp. 47, 62 y ss. 
La protección de la privacidad en la jurisprudencia chilena reciente

con servicios públicos tengan carácter privado, es sencillamente insostenible que el Estado sea titular de la garantía de la inviolabilidad de los documentos privados. El Estado no es titular de derechos constitucionales. Es por ello que los documentos en poder del Estado son por definición públicos, aunque puedan estar sujetos a reserva o secreto. Y según se ha dicho arriba, la Ley de Acceso a la Información determina la reserva o secreto de aquella información cuya "publicidad, comunicación o conocimiento afecte... la esfera de... [la] vida privada" de las personas. Esta es una calificación meramente legal que no puede hacerse sin conocer el contenido de los correos electrónicos respecto de los cuales se solicitaba copia. El Tribunal, al protegerlos con la garantía de la inviolabilidad de las comunicaciones, ha creado una pantalla propicia para la proliferación de prácticas corruptas.

Finalmente, de la consideración conjunta de las sentencias comentadas de la Corte Suprema y del Tribunal Constitucional es posible extraer algunas conclusiones respecto del carácter público o privado de las comunicaciones a través de Internet. ¿Es posible una lectura no contradictoria de ambas? Se recordará que la Corte tuvo presentes las siguientes tres condiciones pragmáticas de la comunicación para concluir que ella no tenía carácter privado: (1) que se realizó en la red pública Internet; (2) que se estableció mediante un programa de libre disposición; (3) que se estableció anónimamente entre múltiples usuarios. De estos requisitos, el primero es compartido por el correo electrónico. El segundo es contingente: el correo electrónico puede enviarse, recibirse y administrarse tanto mediante programas pagados como mediante programas de libre disposición. Y, en todo caso, es difícil entender por qué la naturaleza pagada o gratuita del programa de comunicaciones habría de ser relevante a objeto de determinar el carácter público o privado de la comunicación.

Queda entonces solo el tercer elemento como diferenciador entre ambos casos. La única lectura no contradictoria de ambas sentencias es la que entiende que el carácter público o privado de las comunicaciones establecidas a través de Internet sería o el carácter anónimo de la comunicación o la multiplicidad de interlocutores. ¿Es posible aducir razones a favor de esta lectura? La respuesta es negativa si se atiende a la pluralidad de interlocutores. En efecto, resulta habitual el envío de correo electrónico 
Rodrigo P. Correa G.

a múltiples usuarios que, sin embargo, son claramente determinados y pueden conformar un círculo relativamente cerrado al cual se quiera limitar la comunicación. No es entonces posible descansar en dicha pluralidad para determinar qué comunicaciones están protegidas y cuáles no.

El anonimato de los interlocutores parece ser el único factor que permite trazar una distinción no arbitraria entre la comunicación por correo electrónico y la comunicación P2P. Eso no significa que sea una distinción adecuada en relación con el derecho constitucional a la protección de la vida privada. Pesa a su favor que el riesgo de indiscreción de una comunicación en la que participan anónimamente una multiplicidad de personas, que no tienen más barrera de entrada al círculo de interlocutores que su propia decisión y algunos elementos técnicos, es altísimo. Una expectativa de privacidad parece incoherente con tan alto riesgo. Pesa sin embargo en contra de la distinción el hecho de que dicho riesgo sea administrado por el interlocutor mediante el ocultamiento de su identidad, al comparecer mediante un número IP que no se encuentra públicamente relacionado con aquella. Como sea, la determinación de las condiciones bajo las cuales una comunicación estará protegida es, a fin de cuestas, de derecho positivo. Si el peso de las razones no es decisivo desde el punto de vista constitucional, la lectura propuesta resulta adecuada.

\section{2.}

El año 2015, dos municipios de la ciudad de Santiago licitaron un servicio de vigilancia mediante cámaras de vídeo ubicadas en globos aerostáticos a 150 metros sobre el nivel del suelo. Vecinos solicitaron amparo constitucional por vulneración de su garantía de respeto de la vida privada e inviolabilidad del hogar. La Corte de Apelaciones de Santiago acogió el amparo y ordenó cesar de inmediato todas las actividades de captación, almacenamiento y procesamiento de las imágenes ${ }^{15}$. La Corte Suprema 
La protección de la privacidad en la jurisprudencia chilena reciente

revocó y acogió el amparo parcialmente, imponiendo ciertas condiciones para la operación del sistema ${ }^{16}$.

Tanto la Corte de Apelaciones de Santiago como la Corte Suprema trazaron una línea entre los espacios públicos y el hogar. En relación con los primeros, la Corte de Apelaciones desestimó el recurso en relación con uno de los actores, quien desde su hogar no veía los globos de vigilancia, pero sí desde la parada de buses que utiliza regularmente. Fundamentó esta decisión en que dicho actor

queda afecto a la vigilancia de los implementos dispuestos por la recurrida solamente cuando circula por espacios públicos en los que no puede tener una razonable expectativa de privacidad, puesto que dichos espacios están abiertos a toda clase de personas, sin que... pueda excluir a nadie de ellos, que es lo que al fin y al cabo caracteriza la privacidad, lo que llevará al rechazo del recurso a su respecto ${ }^{17}$

Conforme a este fundamento, la presencia y conducta en el espacio público, en cuanto puede ser vista, no se encuentra dentro del ámbito de protección de la garantía de la protección de la vida privada. Por esta razón, la citada Corte de Apelaciones solo acogió el recurso en cuanto había sido deducido por personas cuyos hogares quedaban en el radio de captación de imágenes (considerando 23).

La decisión de la Corte de Apelaciones de Santiago no fue apelada por quien reclamaba afectación de su vida privada al ser captado en el paradero de buses, de manera que la Corte Suprema no se vio en la necesidad de revisar los fundamentos que tuvo la Corte de Apelaciones para denegarle amparo. En consecuencia, la sentencia de la Corte Suprema no permite afirmar categóricamente si comparte la tesis de la Corte de Apelaciones de Santiago que excluye del ámbito de protección de la garantía la presencia y conducta visible en espacios públicos. Por otra parte, la Corte Suprema sometió la medida a un muy parcial examen de proporcionali-

16 Chile, Corte Suprema, sentencia de 1 de junio de 2016 (rol 18.481-2016).

17 Considerando 22. 
Rodrigo P. Correa G.

$\mathrm{dad}^{18}$. Por una parte, el que la Corte haya realizado este examen sugiere que estimaba que la video vigilancia constituía una afectación prima facie de la garantía de respeto a la vida privada, la que sin embargo podría estar constitucionalmente justificada por el principio de proporcionalidad. Por otra parte, al realizar este examen, la Corte se refirió al espacio público como aquel "donde no puede pretenderse una mayor expectativa de privacidad-exceptuándose actos de intrusión que pueden constituir ilícitos penales". Es difícil entender este caveat de la Corte, pues la protección penal de la privacidad opera en recintos privados o que no sean de libre acceso al público para la captación tanto de conversaciones como de imágenes. Solo la protección penal de documentos privados no está limitada a tales espacios, de manera que la Corte probablemente quiso dejar a salvo la tipicidad de la apertura y registro de papeles privados que porta una persona en la vía pública ${ }^{19}$.

Para el examen de proporcionalidad la Corte asumió que el fin del sistema impugnado era la protección de personas y bienes, la disuasión de los delitos y la obtención de prueba de cargo (considerandos $7^{\circ}$ y $8^{\circ}$ ). En una decisión discutible bajo el principio de vinculación positiva de la administración a la ley, entendió que la ley autorizaba a los municipios a operar un sistema de video vigilancia con tal fin ${ }^{20}$. A continuación constató que el legislador ya había considerado que el sistema de video vigilancia resultaba idóneo para el fin de garantizar la seguridad pública, particularmente en el control de la violencia en los partidos de fútbol (ley 19327). A la Corte esto

18 Sobre el examen de proporcionalidad, Alexy, R., Teoría de los Derechos Fundamentales, Madrid, Centro de Estudios Políticos y Constitucionales, 2001, pág. 111 y ss.

${ }^{19}$ Chile, Código Penal, artículos 146 (delito común) y 155 (delito funcionario). Debido a una pobre técnica legislativa, la deslocalización es controversial tratándose del delito de sustracción y reproducción de documentos privados, tipificado en el artículo 161-A.

${ }^{20}$ La Corte encontró la habilitación legal en el artículo 4(j) de la Ley Orgánica Constitucional de Municipalidades: "Las municipalidades, en el ámbito de su territorio, podrán desarrollar, directamente o con otros órganos de la Administración del Estado, funciones relacionadas con... El apoyo y el fomento de medidas de prevención en materia de seguridad ciudadana y colaborar en su implementación..." Esta disposición ha sido posteriormente modificada. Actualmente contiene la siguiente regla: "así como también adopción de medidas en el ámbito de la seguridad pública a nivel comunal...” Esta nueva habilitación despeja las dudas sobre la compatibilidad del sistema de vídeo vigilancia con la vinculación positiva a la ley. 
La protección de la privacidad en la jurisprudencia chilena reciente

le pareció suficiente como examen de idoneidad, mostrando con ello una significativa y saludable deferencia al legislador y transfiriendo al particular la carga de la prueba de la falta de idoneidad.

La Corte concluyó que "captar imágenes en la vía pública para los propósitos antes descritos constituye una actividad legítima que no puede atentar contra los derechos que se dicen afectados" (considerando $8^{\circ}$ ), habiendo omitido los exámenes de necesidad y de proporcionalidad en sentido estricto ${ }^{21}$. Esta omisión contribuye a la poca claridad de la fundamentación de la Corte, pues no queda claro si las expectativas de no ser filmado en la vía pública carecen por completo de protección constitucional o si, por el contrario, ellas gozan de una protección constitucional débil que cede ante las medidas idóneas para fines de seguridad pública. Esta indeterminación probablemente tendrá que ser encarada en el futuro, para determinar la constitucionalidad de conductas tales como la fotografía de los manifestantes en una protesta en la vía pública.

Que el hogar se encuentra dentro del ámbito de protección de la garantía constitucional de la inviolabilidad del hogar es una obviedad. No extraña entonces que así lo hayan estimado tanto la Corte de Apelaciones de Santiago como la Corte Suprema. No es sin embargo tan obvio respecto de qué es lo que el hogar está protegido. Es claro que protege frente al ingreso físico al hogar y a su registro físico, pues la disposición constitucional dispone que este "solo puede allanarse... en los casos y formas determinados por la ley”. ¿Pero alcanza la protección a la pretensión de registrar desde fuera del hogar imágenes o sonidos de lo que ocurre dentro del mismo? Tanto la Corte de Apelaciones como la Corte Suprema respondieron afirmativamente, al menos en lo que respecta al registro de imágenes (pues el caso no trataba de registros sonoros). En consecuencia, no tuvieron dificultades para concluir que los globos de video vigilancia afectaban en la inviolabilidad del hogar en cuanto podían registrar imágenes de lo que ocurría en los hogares. Alcanzada esta conclusión, habría

${ }^{21}$ La Corte Suprema concluyó que por esta razón no se justificaba la decisión de la Corte de Apelaciones de Santiago de declarar inconstitucional el sistema de globos de vigilancia. Esta conclusión está fuera de lugar, pues según se ha dicho en el texto principal, la Corte de Apelaciones fundó su decisión en la inviolabilidad del hogar exclusivamente. 
Rodrigo P. Correa G.

correspondido preguntar si dicha afectación se encontraba constitucionalmente justificada. Ambas cortes omitieron sin embargo este examen y declararon que la medida era inconstitucional en cuanto permitía captar imágenes de los hogares. Esto significa que ambas cortes estiman que la afectación a la inviolabilidad del hogar no estaba justificada, para lo cual no dieron sin embargo razones. Pero estas probablemente se encuentran en la extensión analógica de la regla constitucional, que en relación con el allanamiento parece al menos subordinar la posibilidad de ponderación judicial a la ponderación legislativa ${ }^{22}$.

Habiendo estimado que los globos de vigilancia eran inconstitucionales en cuanto constituyen vulneración a la inviolabilidad del hogar, la Corte de Apelaciones de Santiago determinó como medida de protección que las municipalidades recurridas "deberán cesar de inmediato las actividades de captación, almacenamiento y procesamiento de las imágenes que se realizan por medio de los globos de vigilancia..." La Corte Suprema, aunque revocó esta decisión, acogió parcialmente el recurso y sometió los globos a un particular "régimen de autorización". La principal condición de este régimen es consistente con la fundamentación de la Corte: "El ámbito físico a grabar se delimita a los lugares públicos...” Pero a continuación sigue una calificación, acordada con un voto en contra (Sandoval), para la que no se encuentra justificación alguna en la sentencia: "y de los espacios privados abiertos cuando se trate del seguimiento de un hecho que pueda constituir la comisión de un ilícito". La explicación más plausible de esta calificación es que la mayoría de la Tercera Sala de la Corte Suprema estima que los jardines, patios y terrazas privados constituyen un espacio con un nivel intermedio de protección constitucional de la privacidad, superior al que esta recibe en el espacio público, pero inferior a la que recibe bajo el techo del hogar. En este espacio de protección intermedia, la afectación se encontraría constitucionalmente justificada. Es lamentable que la Corte no haya explicitado las razones de esta conclusión.

${ }^{22}$ Esto significa que no habría posibilidad de declarar judicialmente justificado un allanamiento fuera de los "casos y formas determinados por la ley". Pero la ponderación judicial todavía puede tener lugar cuando la ley otorga al juez competencia para autorizar un allanamiento, como ocurre con el artículo 205 del Código Procesal Penal. 
La protección de la privacidad en la jurisprudencia chilena reciente

3.

La Constitución ha incorporado un mandato de "protección a la vida privada". En el ámbito de las comunicaciones privadas, este mandato se ha satisfecho mediante la criminalización (1) de las intromisiones en las comunicaciones privadas y (2) de la divulgación de dichas comunicaciones; la sanción administrativa a estaciones de televisión por (3) intromisiones en las comunicaciones privadas y (4) por divulgación de dichas comunicaciones; (5) la limitación de las facultades de control y supervisión del empleador respecto de las comunicaciones privadas de sus trabajadores; (6) la ineficacia probatoria en asuntos criminales, de familia y laborales, de registros de conversaciones privadas obtenidos mediante intromisión, y (7) el deber de indemnizar las intromisiones en las comunicaciones privadas. Estos desarrollos plantean dificultades tanto en relación con la calificación de lo que constituye una comunicación privada como respecto de las conductas que califican como intromisión antijurídica en dichas comunicaciones y de las circunstancias que pueden justificar una afectación de las comunicaciones privadas.

Periodistas de un programa de televisión de denuncia tuvieron conocimiento de médicos que extendían licencias médicas falsas. Visitaron a dichos médicos simulando ser pacientes en busca de licencia médica. Durante las consultas grabaron la conversación con una cámara oculta que no fue advertida por los médicos. La filmación fue posteriormente divulgada por televisión. Se planteó el problema de determinar si estos hechos eran constitutivos de los delitos de grabación no autorizada y de divulgación de conversaciones privadas, contemplados en el artículo 161-A del Código Penal. No cabe duda de que estos delitos fueron introducidos el año 1995 en el Código Penal en cumplimiento del mandato constitucional de protección de la vida privada: ellos se incorporaron en un nuevo párrafo quinto titulado "De los delitos contra el respeto y protección a la vida privada y pública de la persona y su familia” del Título III “De los Crímenes y Simples Delitos que Afectan los Derechos Garantidos por la Constitución”23.

${ }^{23}$ La referencia a la "vida... pública" en el párrafo quinto del Título III confirma que se trata de delitos que desarrollan la garantía constitucional del numeral cuarto del artículo 19. Véase supra n. 2. 
Rodrigo P. Correa G.

En fallo dividido de casación en el fondo, la mayoría de la Segunda Sala de la Corte Suprema estimó que no se trataba de conductas típicas ${ }^{24}$. Los tipos penales exigen que se trate de "conversaciones o comunicaciones de carácter privado". La Corte estimó que las conversaciones grabadas no tenían tal carácter. El razonamiento clave fue el siguiente:

el carácter privado de una conversación no está reservado a todo aquello que el titular otorgue esa denominación, porque podría llegarse a extremos de subjetivización [sic] en que carecería de toda certeza la conducta que el tipo penal reprime. Sí puede afirmarse que el carácter privado desaparece cuando se trata de conductas que revisten un interés público.

Este argumento es falaz. Parte de una premisa falsa: el carácter privado de la comunicación está dado o exclusivamente por la expectativa de uno de los interlocutores, o por el interés público de su contenido. No habría una tercera alternativa. Como la primera alternativa es manifiestamente falsa, ya la premisa confirma la conclusión a la que la Corte quiere llegar: lo que determina el carácter privado de la comunicación es el interés público en su contenido. Más que un genuino razonamiento, se trata de una petición de principios. Porque lo cierto es que, como demuestra la jurisprudencia del Tribunal Constitucional arriba comentada, existe una tercera alternativa: el carácter privado de una comunicación puede estar dado por las condiciones pragmáticas en que ella se produce ${ }^{25}$. La correspondencia epistolar no deja de estar constitucional y penalmente protegida porque el contenido de la comunicación tiene interés público ${ }^{26}$.

${ }^{24}$ Chile, Corte Suprema, sentencia de casación de 21 de agosto de 2013 (rol 8393-2012).

25 A igual conclusión había llegado la propia Corte Suprema, que en un caso anterior mediante sentencia de reemplazo confirmó la condena por la grabación subrepticia realizada por uno de los interlocutores de su conversación con un juez, a pesar de que el contenido de la conversación tenía un alto y manifiesto interés público. Chile, Corte Suprema, sentencia de reemplazo de 9 de agosto de 2007, rol 3005-2006.

${ }^{26}$ La apertura y la divulgación de correspondencia ajena cometidas por particulares constituyen delitos especiales y se encuentran en el artículo 146 del Código Penal. La interceptación, apertura, divulgación del contenido y retardo en la entrega de correspondencia, cometidos por empleados del servicio de correspondencia, también constituyen delitos especiales, contemplados en el artículo 156 del mismo Código. La circunstancia de que 
La protección de la privacidad en la jurisprudencia chilena reciente

Resuelto por la Corte que es la presencia o ausencia de interés público en el contenido de la comunicación lo que determina su carácter público o privado, debía determinar si tal interés estaba o no presente en las conversaciones de que aquí se trataba. Sobre este particular sostuvo que

si bien no se ha demostrado la comisión de un ilícito por los presuntos perjudicados, lo cierto es que su conducta importa al menos una transgresión a la ética por parte de profesionales de la salud que otorgaban licencias médicas falsas en desmedro de los demás cotizantes de los sistemas de salud, cuestión que reviste un interés público con mérito suficiente para ser socializada lo que permitirá en último término, el fin de una situación reprobable e inconveniente.

...no ha podido estimarse que la conversación de los periodistas con la profesional sea de carácter privado, pues se refiere a hechos que revelan irregularidades de la praxis médica verificables para ante la opinión pública.

En apoyo de esta conclusión, la sentencia invoca disposiciones de la ley 19733 sobre Libertades de Opinión e Información y Ejercicio del Periodismo que definen el interés público. Esta invocación resulta doblemente defectuosa. En primer lugar, la única disposición de dicha ley que pudiera ser relevante para el caso es la que define de interés público los hechos "realizados en el ejercicio de una profesión u oficio y cuyo conocimiento tenga interés público real". Se trata sin embargo de una definición circular, de la que solo se puede escapar mediante reconducción a alguna otra circunstancia definitoria de un interés público. Por otra parte, otra disposición de la misma ley señala como de interés público "Las actuaciones que, con el consentimiento del interesado, hubieren sido captadas o difundidas por algún medio de comunicación social”. Esta explícita exigencia de consenti-

estos tipos penales utilicen la voz "correspondencia" en vez de la frase "conversaciones o comunicaciones privadas" puede servir para resistir la conclusión que se rechaza en el texto principal, aun aceptando como correcta la doctrina de la Corte Suprema en relación con las conversaciones que ocurren "cara a cara". Pero debe concederse que esta solución formal es intensamente asistemática. 
Rodrigo P. Correa G.

miento del interesado sugiere que, a falta de regla clara que exima de dicho consentimiento, ningún interés público es tal que autorice la captación y difusión no consentidas de comunicaciones realizadas bajo expectativas de privacidad y condiciones pragmáticas consistentes con dichas expectativas.

En segundo lugar, la definición de interés público en la ley 19733 está hecha para la finalidad especialísima de determinar cuándo es admisible la exceptio veritatis ante la acusación de haber cometido el delito de injurias a través de un medio de comunicación social. Pero aquí no se trataba de una acusación por injurias, sino de defraudación de la expectativa de privacidad mediante la video grabación no autorizada de una conversación mantenida en condiciones adecuadas a dicha expectativa. No hay razón alguna para entender que la autorización para hacer imputaciones que, siendo verdaderas y de interés público, puedan resultar injuriosas (todo lo cual se mueve en el ámbito de la protección de la honra y no de la privacidad), signifique autorización para afectar la privacidad ${ }^{27}$.

En cuanto el tipo penal sanciona conductas relativas a "conversaciones y comunicaciones de carácter privado" los argumentos reseñados resultaban suficientes para casar la sentencia condenatoria y para dictar sentencia de reemplazo absolutoria. Sin embargo, en la sentencia de reemplazo la mayoría introdujo un argumento adicional, consistente en que no se incurre en la conducta típica cuando quien graba la conversación es partícipe en la misma ${ }^{28}$. Esta afirmación resulta en principio plausible. No cabe duda de que en ausencia de un deber de reserva, la indiscreción de quien revela el contenido de una conversación privada no constituye delito. En este sentido, el derecho pone de cargo del partícipe en una comunicación el riesgo de indiscreción de sus interlocutores. Y si esto es así, parece consistente considerar atípico el registro no autorizado que uno de los interlocutores hace de la comunicación: el derecho haría soportar a cada partícipe en una conversación el riesgo de ser grabado por los demás, al igual que el riesgo

${ }^{27}$ Bascuñán, A., "Grabaciones Subrepticias en el Derecho Penal Chileno. Comentario a la Sentencia de la Corte Suprema en el Caso Chilevisión II", Revista de ciencias penales, XLI, 3, 2014, pp. 43 y 61 y ss.

28 Chile, Corte Suprema, sentencia de reemplazo de 21 de agosto de 2013 (rol 8393-2012). La Corte citó a Politoff, S., Matus, J.P. y Ramírez, M.C., Lecciones de Derecho Penal Chileno. Parte Especial, Santiago, Jurídica de Chile, 2004, pág. 239. 
La protección de la privacidad en la jurisprudencia chilena reciente

de indiscreción. Hay sin embargo al menos dos razones que controvierten esta conclusión. Por una parte, los registros fonográficos o videográficos permiten una reproducción que resulta significativamente más dañina para la privacidad que la mera indiscreción ${ }^{29}$. La atipicidad de la conducta menos dañina no puede justificar la atipicidad de la conducta más dañina. Por otra parte, la atipicidad resulta asistemática. Quienes mantienen una comunicación privada pretenden excluir a terceros de la misma, sin importar si estos terceros perciben la comunicación a través de sus sentidos sin auxilio tecnológico alguno o si lo hacen con dicho auxilio, y sin importar tampoco si la perciben en el momento en que ella se produce o en un momento posterior. El derecho protege esta expectativa de exclusión. Es indudable que es típica la conducta del tercero que con autorización de sólo uno de los partícipes en la conversación oculta un micrófono y graba esta conversación. No se comprende qué justificaría levantar esta protección cuando ese tercero accede a igual registro realizado subrepticiamente por uno de los interlocutores ${ }^{30}$.

Adicionalmente, la filmación de imágenes, la grabación de comunicaciones entre personas presentes y la grabación de conversaciones telefónicas con el fin de investigación de delitos están sujetas a severas limitaciones: ellas deben ser autorizadas judicialmente y solo pueden serlo cuando los hechos investigados merezcan pena de crimen. No es plausible sostener que fiscales y policías puedan eludir estas limitaciones mediante la infiltración en las redes criminales para incorporarse en sus comunicaciones $y$, entonces, registrarlas subrepticiamente sin autorización judicial. Y si esta interpretación no es plausible, tampoco lo es aquella que libera a los periodistas e investigadores privados de las restricciones a que están sujetos fiscales y policías.

El problema del carácter privado de las conversaciones también surgió en el contexto de un juicio laboral por prácticas antisindicales ${ }^{31}$. En el contexto de un proceso de negociación colectiva, un grupo de trabajadores en

${ }^{29}$ Bascunán, op. cit., pág. 57.

${ }^{30}$ Ibidem, pág. 59 y ss.

${ }^{31}$ El autor conoció de este caso en su calidad de abogado integrante de la Corte Suprema y disintió de la decisión de la mayoría por razones procedimentales que, sin embargo, importan una toma de posición sobre algunas de las cuestiones de fondo que aquí se comentan. 
Rodrigo P. Correa G.

huelga llegó a acuerdo con el empleador. Un representante del empleador se reunió a puertas cerradas con grupos de no más de ocho de estos trabajadores descolgados de la huelga. En dichas reuniones el representante de la empresa hizo afirmaciones cuyo sentido performativo era constitutivo de prácticas antisindicales. Una de estas reuniones fue subrepticiamente grabada por uno de los trabajadores. La pregunta que tuvieron que enfrentar los tribunales es si dicha grabación podía ser valorada para dar por acreditadas las prácticas antisindicales en el juicio incoado contra el empleador. La disposición pertinente estaba dada por el artículo 453 No 4 del Código del Trabajo: "carecerán de valor probatorio y, en consecuencia, no podrán ser apreciadas por el tribunal las pruebas que las partes aporten y que se hubieren obtenido directa o indirectamente por medios ilícitos o a través de actos que impliquen violación de derechos fundamentales".

La Corte Suprema concluyó que, no obstante que la disposición transcrita parece comprender dos hipótesis, se trata en realidad de una sola, relativa a la violación de derechos fundamentales ${ }^{32}$. Esta decisión importaba desestimar la relevancia de los tipos penales reseñados en el comentario a la sentencia precedente. Esta decisión no resulta determinante para el presente comentario, pues al establecer el citado artículo 453 № 4 una referencia directa a los derechos fundamentales, la Corte se vio en todo caso obligada a examinar si la conversación grabada tenía carácter privado. Concluyó que no lo tenía, y que por lo tanto la grabación no había vulnerado derechos fundamentales. Tuvo para ello en consideración que un conjunto de circunstancias determinaba que la expectativa de privacidad del representante de la empresa no era razonable. En primer lugar, el contexto en que tuvo lugar la conversación: conflicto laboral que dio lugar a una huelga prolongada; conversación con trabajadores descolgados de la misma pero todavía miembros del sindicato; asistencia de varias personas

El lector queda advertido de que la imparcialidad académica del autor puede verse afectada por esta circunstancia.

32 El autor de este trabajo disintió en este punto. Para una crítica a esta parte de la fundamentación de la sentencia, véase Marín, R., "A propósito de la sentencia de la prueba ilícita en el ámbito laboral", El Mercurio Legal, 18 de mayo de 2018, disponible en http://www. elmercurio.com/Legal/Noticias/Opinion/2018/05/18/A-proposito-de-la-sentencia-de-laprueba-ilicita-en-el-ambito-laboral.aspx. 
a la reunión, aumentando el riesgo de divulgación de lo comunicado; contenido de lo conversado, que era de manifiesto interés para los miembros del sindicato. En segundo lugar, el hecho de no haberse advertido a los asistentes que se trataba de una reunión de carácter reservado. En tercer lugar, que lo conversado "no dice relación con la esfera privada de quien las emitió ni constituyen, en caso alguno, el develamiento de algo reservado a su ámbito más íntimo" (considerando séptimo).

Las consideraciones de contexto que la Corte considera relevantes son problemáticas por tres razones. En primer lugar, algunas determinan que el grado de protección de la privacidad disminuya a medida que aumenta el interés de terceros en conocer el contenido de la comunicación. Tal es el caso, en particular, de que la "índole netamente laboral" de lo conversado "resultaba de interés para el resto de los integrantes de la entidad sindical". Eso se aleja de lo que tradicionalmente ha sido la protección de las comunicaciones privadas, que busca definir medios o espacios que se protegen con completa independencia del interés que terceros pudieran tener en acceder a lo que allí ocurre. En segundo lugar, es cierto que el riesgo de indiscreción lo asume quien comunica. Esto no depende, sin embargo, del número de interlocutores. Incluso quien confía un secreto preciado a su mejor amigo asume el riesgo de la indiscreción de este último. Eso no significa, según se ha dicho más arriba, asumir el riesgo del registro fonográfico o videográfico. En tercer lugar, de la circunstancia fáctica de que aumente el riesgo de registro subrepticio no se sigue per se desprotección jurídica. Esto debiera ser evidente. Quien necesita comunicar reservadamente un mensaje del que sabe que existe tal interés por conocerlo que hay alto riesgo de grabación subrepticia, no deja de tener derecho a la privacidad ni protección constitucional y legal para transmitir el mensaje.

No cabe duda de que la privación de valor probatorio en los juicios laborales a los fonogramas o videos de una comunicación privada obtenidos sin autorización de los interlocutores constituye un desarrollo del deber constitucional de proteger la vida privada. En efecto, ambas hipótesis del artículo 453 No 4 del Código del Trabajo remiten a la garantía constitucional de la vida privada. La primera lo hace indirectamente, pues al referirse a las pruebas obtenidas "directa o indirectamente por medios ilícitos", inevitablemente pasa por el artículo 161-A del Código Penal el cual, según se ha explicado 
Rodrigo P. Correa G.

más arriba, constituye explícitamente un desarrollo de la citada garantía. La segunda lo hace directamente, al referirse a "actos que impliquen violación de derechos fundamentales". Que la privación de valor probatorio sea desarrollo del deber constitucional de protección de la vida privada no significa sin embargo que sea un desarrollo que venga exigido por dicho deber, pues nada impide que el legislador proteja un derecho más intensamente de lo que la Constitución exige. Hay buenas razones para pensar que tal es el caso tratándose de las reglas de exclusión de prueba o denegación de valor probatorio a las mismas. En este sentido, la sentencia que se comenta importa una reducción del ámbito de protección de la privacidad, pero no parece quedar bajo el umbral constitucionalmente exigido. En este punto, sin embargo, es necesario distinguir entre la decisión de la Corte y su fundamentación. La decisión se limita a establecer que los tribunales pueden valorar la grabación subrepticia de una conversación en el ámbito laboral que sirve para acreditar prácticas antisindicales. La fundamentación es sin embargo mucho más amplia. Ella importa negar carácter privado a comunicaciones sostenidas bajo expectativas normativas de privacidad en condiciones pragmáticas coherentes con dichas expectativas ${ }^{33}$. Si esta fundamentación es asumida como correcta y se extraen las consecuencias que de ella se sigue, posiblemente se caería bajo el umbral de protección constitucionalmente exigido. La Corte podría haber alcanzado la misma decisión con una fundamentación menos lesiva para la protección de la vida privada. En efecto, pudo haber sostenido que la regla que priva de valor probatorio está establecida única-

${ }^{33}$ Esta interpretación amplia de la fundamentación puede ser resistida afirmando que las condiciones pragmáticas en que ocurrió la grabación eran incoherentes con una expectativa de privacidad. Es importante tener presente lo que esta lectura implica: la conversación no puede ser privada para algunos interlocutores y para otros no. Si las condiciones en que la conversación se desenvuelve son incoherentes con expectativas de privacidad, esto vale para todos los interlocutores. Lo cual significaría que el empleador no incurriría en falta si fuera él quien registrara la conversación. Por cierto, sería en todo caso imprescindible determinar cuáles son las condiciones pragmáticas precisas que determinan que no sea razonable una expectativa de privacidad (¿que la reunión ocurre en la empresa? ¿que los temas tratar son laborales? ¿que ella se da en el contexto de una negociación colectiva?). 
La protección de la privacidad en la jurisprudencia chilena reciente

mente a favor del trabajador, argumento que resulta plausible a la luz de los principios del derecho laboral ${ }^{34}$.

Recientemente, la Corte de Apelaciones de Santiago ha conocido de otro interesante asunto relativo a la protección de la vida privada en el ámbito de las relaciones laborales ${ }^{35}$. Una empresa de estudios de mercado y de opinión tomó accidentalmente conocimiento de antecedentes que justificaban sospechar que una de sus trabajadoras filtraba información a una empresa de la competencia. A objeto de confirmar esta sospecha, la empresa estimó necesario revisar la correspondencia electrónica de la trabajadora:

[L]a denunciada no ha interceptado las comunicaciones de la actora mientras eran enviados o recibidos los correos electrónicos, ni ha afectado de otro modo el proceso de comunicación, sino que ha conocido su existencia y contenido a posteriori, una vez que quedó almacenado en el computador de la empresa (considerando segundo $)^{36}$.

En consecuencia, a pesar de que la Corte afirmó que "se debe discernir acerca del alcance y límites del poder de vigilancia y control del empresario cuando puede derivar en una posible afectación del derecho constitucional al secreto de las comunicaciones", lo cierto es que se trata más bien de una posible afectación de la garantía de la inviolabilidad de los documentos pri$\operatorname{vados}^{37}$. El reglamento interno de la empresa autorizaba este registro sujeto a la condición de que estuviera presente el trabajador afectado. Aunque se

34 Tal fundamentación no habría excluido el carácter de injusto penal de la grabación subrepticia. Aunque la sentencia de la Corte no se pronuncia sobre la cuestión penal y su fundamentación intenta eludirla mediante la reducción de las hipótesis de legalidad y de constitucionalidad del artículo 453 № 4 del Código del Trabajo a una única hipótesis de constitucionalidad, fracasa en su intento. Las razones para estimar que la conversación no tenía carácter privado tienden a proyectarse directamente a la pretensión de aplicar del artículo 161-A del Código Penal.

${ }^{35}$ Chile, Corte de Apelaciones de Santiago, sentencia de reemplazo de 9 de febrero de 2018, rol 2134-2017. Contra esta sentencia la demandante dedujo recurso de unificación de jurisprudencia, el que ha sido admitido a tramitación por la Corte Suprema y, a la fecha de esta redacción, se encuentra con decreto de "autos en relación".

${ }^{36}$ La Corte insistió en el mismo punto en el considerando séptimo.

37 Véase supra. 
Rodrigo P. Correa G.

invitó a la trabajadora a participar en la indagación, ella rehusó participar alegando que se encontraba bajo licencia médica. La empresa realizó el registro sin su presencia.

La Corte de Apelaciones estimó justificada la conducta del empleador. Tuvo para ello presente que la empresa se encuentra bajo obligación legal de reserva de los datos personales que recoge a fin de prestar los servicios propios de su giro. La filtración de información podía entonces poner a la empresa en situación de infracción de ley. En consecuencia, para la empresa tomar medidas de protección no constituía solo una finalidad legítima, sino una obligación legal. Luego la Corte ponderó dichas medidas con la afectación a la inviolabilidad de las comunicaciones de la trabajadora. Estimó que la medida se encontraba justificada, primero, porque al advertir el reglamento interno la posibilidad de registro, la trabajadora no podía tener una razonable expectativa de privacidad y, segundo, porque el proceso de comunicación ya se encontraba finalizado. Agregó que la inviolabilidad de las comunicaciones privadas no es un derecho absoluto.

Algunos aspectos de esta fundamentación son débiles. Por una parte, la circunstancia de que la comunicación ya se encontraba finalizada es irrelevante para determinar si se encuentra afectada la acción del empleador bajo la garantía de la inviolabilidad de las comunicaciones privadas. Ella constituye, según se ha defendido más arriba, una razón para estimar que la garantía relevante es la de la inviolabilidad de los documentos privados. Y tratándose de esta garantía, la circunstancia de que se trate de una comunicación en curso o de registros de comunicaciones pasadas resulta irrelevante. Por otra parte, no cabe sin más deducir del carácter no absoluto de los derechos en general que la acción del empleador se encuentra justificada. El numeral quinto es categórico: por una parte, se trata de una inviolabilidad; por otra parte, es explícito en que "las comunicaciones y documentos privados interceptarse, abrirse o registrarse en los casos y formas determinados por la ley". Finalmente, el mandato de protección a la vida privada se encuentra en el cuarto y no en el quinto numeral del artículo 19 de la Constitución. En este punto se encuentra la clave de la correcta solución al problema.

La inviolabilidad que garantiza el numeral quinto del artículo 19 de la Constitución es una garantía frente al Estado. No es en consecuencia aplicable a un problema entre particulares. En este último caso, sí es relevante 
el deber de "protección a la vida privada". Esta protección naturalmente puede extenderse a las comunicaciones y documentos privados, pero no ya necesariamente como una inviolabilidad que solo pueda ser afectada "en los casos y formas determinados por la ley”. Así justificada, resulta razonable la conclusión de la Corte de Apelaciones de Santiago en el sentido de que el empleador obligado a cautelar el cumplimiento de sus obligaciones legales está justificado en examinar documentos electrónicos privados de sus trabajadores que se encuentren en computadores de la empresa. Por cierto, cabe agregar que el empleador no solo actúa legítimamente en cumplimiento de obligaciones legales, sino también como dueño y empresario que busca maximizar su utilidad. Este caso no resuelve la pregunta de si se encuentra justificado igual registro por el empleador cuando se hace con la única finalidad de aumentar la productividad de la empresa. Ya tendrán ocasión los tribunales de enfrentarse a tal problema.

\section{4.}

Las disposiciones constitucionales relativas a la vida privada, aunque parcas, ofrecen un marco adecuado al desarrollo legislativo y a la jurisprudencia. Ninguno de estos desarrollos ha sido satisfactorio. En particular, la jurisprudencia ha sido vacilante y contradictoria para definir qué comunicaciones tienen protección constitucional; los fundamentos de sus decisiones han sido débiles y, por último, el Tribunal Constitucional ha extendido injustificadamente la protección a las comunicaciones privadas a áreas ajenas a su ámbito de protección.

En efecto, la jurisprudencia en ocasiones ha delimitado las condiciones puramente formales bajo las cuales una comunicación tiene carácter privado y queda por tanto protegida con independencia de su contenido, mientras que a veces ha denegado tal carácter a dichas comunicaciones cuando están revestidas de "interés público", manifestando así un débil compromiso con la protección de la privacidad frente a las presiones colectiva.

Por otra parte, sentencias como la de los globos de vigilancia o la de la potestad de inspección del empleador, que han trazado distinciones razonables y fructíferas, han dejado pasar la oportunidad para fundar 
Rodrigo P. Correa G.

adecuadamente sus distinciones. Por último, el Tribunal Constitucional ha extendido injustificadamente a los documentos en poder del Estado la garantía de la inviolabilidad de las comunicaciones privadas, constitucionalizando así un problema que, por explícito mandato constitucional, es de orden legislativo.

\section{Bibliografía}

Alexy, R., Teoría de los Derechos Fundamentales, Madrid, Centro de Estudios Políticos y Constitucionales, 2001.

Bascuñán, A., "Grabaciones Subrepticias en el Derecho Penal Chileno. Comentario a la Sentencia de la Corte Suprema en el Caso Chilevisión II", Revista de ciencias penales, XLI, 3, 2014.

Böckenförde, E.W., "La Democracia como Principio Constitucional", en Estudios sobre Estado de Derecho y Democracia, Madrid, Trotta, 2000.

Marín, R., "A Propósito de la Sentencia de la Prueba Ilícita en el Ámbito Laboral", El Mercurio Legal, 18 de mayo de 2018, disponible en http://www.elmercurio.com/Legal/Noticias/Opinion/2018/05/18/Aproposito-de-la-sentencia-de-la-prueba-ilicita-en-el-ambito-laboral. aspx.

Politoff, S., Matus, J.P. y Ramírez, M.C., Lecciones de Derecho Penal Chileno. Parte Especial, Santiago, Jurídica de Chile, 2004. 